\title{
A Proposal of Interaction Modelling Formalisms in Virtual Collaborative Work Spaces
}

\author{
Dario Rodriguez and Ramon Garcia-Martinez
}

\begin{abstract}
The virtual collaborative workspaces allow integration of work groups in which members are not physically contiguous. There is a vast literature related to modeling of software architectures that support this type of environment. However, the existing formalisms model the interaction between actors and between system and system components. In this context, this paper proposes modeling artifacts (which supplement the existing) to describe: domain vocabulary through table category-concept-definition; interactions among actors through interaction cases, interaction group diagrams, interaction procedures and sequence diagram of group dynamics; and development by group of conceptual artifacts through diagram of development of conceptual objects. we present a proof of concept to illustrate the proposal.
\end{abstract}

Index Terms-Virtual spaces, collaborative work, conceptual modeling formalisms.

\section{INTRODUCTION}

Collaborative work is based on communication and exchange of information between individuals in order to develop a conceptual object [1], [2]. Systems within the paradigm Computer Supported Cooperative Work (CSCW) constitute an approach [3] to facilitate group work processes mediated by information technology [4].

It has been proposed [5] that there are three main lines of systems development within the paradigm of CSCW:

1) Development ad-hoc, in which systems are built in a completely adapted way to the specific problem to which it is intended to support, this has been, until now, the usual trend in creating groupware systems.

2) The use of programming toolkits, which provide a higher level of programming abstraction through functions and APIs (Application Programmer Interface).

3) The development of CSCW systems based on components that allow the construction of CSCW systems using predefined building blocks that can be reused and combined in different ways.

Moreover, Molina and colleagues [5] indicate that another line of development is proposed to base the development process in the conceptual modelling of the collaborative virtual environment. There are some proposals for conceptual modelling notations of aspects of group work. Among these notations may be mentioned: a) APM (Action Port Model)

Manuscript received May 5, 2013; revised September 10, 2013. This work was supported in part by Research Project 33A166, Department of Productive and Technological Development, National University of Lanus, Argentina.

The authors are with the Research and Development Lab in Working Virtual Spaces within Information Systems Research Group, National University of Lanus. Argentina (e-mail: darodriguez@unla.edu.ar, rgarcia@unla.edu.ar). focused on modeling the workflows developed by groups [6]; b) PROCLETS that proposes a notation for interaction processes associated with managing multiple workflows [7]; c) AMENITIES, that proposes extensions of UML notation (COMO-UML) for groupware modelling with emphasis on the modelling of dynamic aspects [8]; and d) UML-G, also focuses on the modelling of groupware but with emphasis on data modelling [9], [10]

This chapter defines the problem of modelling the interactions in a working group (Section II), proposes an integrated modelling framework (Section III) composed of formalisms: Table Category-Concept-Definition (Section III.A), Interaction Cases and Interaction Group Diagrams (Section III.B), Interaction Procedures (Section III.C), Sequence Diagram of Group Dynamics (Section III.D), and Diagram of Development of Conceptual Objects (Section III.E); presents a concept proof of the introduced formalisms (Section IV); and formulates conclusions and future research lines (Section V).

\section{DEFINITION OF THE PROBLEM}

Several authors [5], [11]-[13] have pointed out the need to address prior to CSCW system modelling; the modelling of aspects of group dynamics such as social interactions and responsibilities among individual, noting that the current state of conceptual modelling work group is characterized by the following limitations:

1) Lack of theoretical and computational models that allow to specify adequately the group activities mediated by information technology.

2) Difficulty in addressing the integral modelling of interactive aspects among individuals and task aspects of group work.

3) Lack of adequate conceptual specification artifacts for modelling collaborative tasks that have to be mediated by CSCW systems.

In the context of formalisms to develop the analysis and design of $\mathrm{CSCW}$ it may be done the following research question: Is it possible to develop new modelling formalisms, to complement ones previously presented, to model interactions among group members and its social dynamic, which should be managed by CSCW systems?

\section{PRoposed SOLUTION}

The proposed framework for analysis and design of virtual spaces oriented to collaborative work is composed by the following modelling formalisms: Table Category-ConceptDefinition (presented in Section III.A), Interaction Cases and 
Interaction Group Diagrams (presented in Section III.B), Interaction Procedures (presented in Section III.C), Sequence Diagram of Group Dynamics (presented in Section III.D), and Diagram of Development of Conceptual Objects (presented in Section III.E).

\section{A. Proposed Formalism: Table Category-Concept- Definition}

In the context of formalisms for knowledge representation proposed by the Knowledge Engineering [14], [15], in [16] was introduced Table "Concept-Category-Definition" (Table CCD) whose function is to represent the factual knowledge of the conceptual model of group dynamics. The CCD table introduces, in lexicographic order, the concepts that are going to be used in other formalisms specifying the category and giving the concept definition. The formalism is captured as a table as shown in Table I.

TABLE I: EXAMPLE OF TABLE CATEGORY-CONCEPT-DEFINITION

\begin{tabular}{lll}
\hline Concept & Category & Definition \\
\hline Concept 1 & Category 1 & Definition of Concept 1 \\
Concept 2 & Category 1 & --- \\
--- & --- & --- \\
Concept N & Category Q & Definition of Concept N \\
\hline
\end{tabular}

A concept can be of any of the following categories: actor, object or interaction. Actors are who bring to life the group dynamics. Objects are the entities that receive the exercise of the powers of the actors interaction. The interactions define processes that actors agree to perform on objects.

\section{B. Proposed Formalism: Interaction Cases and Interaction Group Diagrams}

The modelling of the interactions between actors are made using two formalisms: [a] Interaction Cases and [b] Interaction Group Diagrams. An Interaction Case captures interactions between two actors (see Fig. 1).

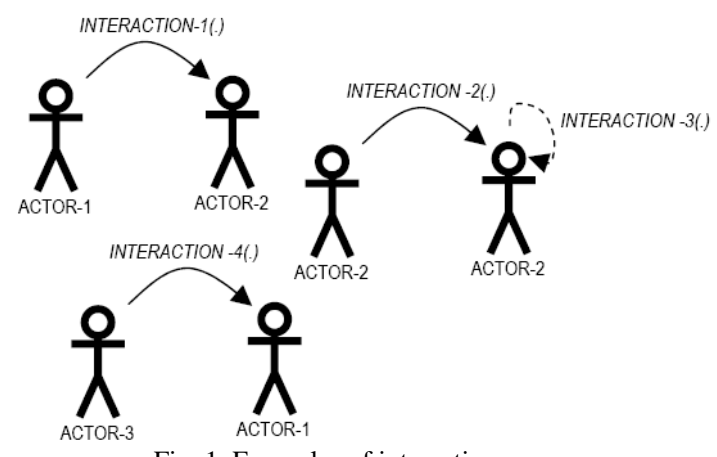

Fig. 1. Examples of interaction cases.

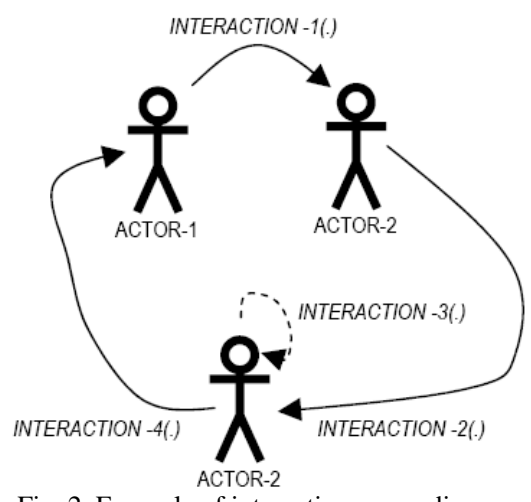

Fig. 2. Example of interaction group diagram.
In particular, the reflection is a case of interaction of an actor with himself. An Interaction Group Diagram provides, in an integrated way, interactions among all actors considered in the modelling process (see Fig. 2).

The notation proposed for Interaction Cases and Interaction Group Diagrams is based on use-cases and use-case diagrams [17], [18], except that in the objects paradigm are modelled interactions between actors and the system, and is not considered the interactions among actors.

In the formalism proposed in this chapter, are used solid lines to model interactions between actors and dotted lines to model the reflections of an actor.

\section{Proposed Formalism: Interaction Procedures}

The procedures describe the composition of interactions among the actors made for the development of an object. To express the procedures that actors can perform on the objects, is proposed to use predicates of order $N$ [19], [20]. It is used prefix notation and the used grammar shown in Table II.

\section{TABLE II: GRAMMAR FOR EXPRESSING PROCEDURES}

$$
\begin{array}{lll}
<\text { ACTION }> & ::= & <\text { Action } 1>\mid<\text { Action } 2>|\ldots| \\
& <\text { Action } \mathrm{P}> \\
<\text { ACTOR }> & ::= & <\text { Actor } 1>\mid<\text { Actor } 2>|\ldots|<\text { Actor } \mathrm{Q}> \\
<\text { OBJECT }> & ::= & <\text { Object } 1>\mid<\text { Object } 2>|\ldots|<\text { Object } \mathrm{N}> \\
<\text { PROCEDURE }>::= & <\text { ACTION }>\text { "(" }<\text { ACTOR }>\text { "," }<\text { OBJECT }>\text { ")" } \mid \\
& <\text { ACTION }>\text { "("<ACTOR }>\text {," } \\
& <\text { PROCEDURE }>\text { ")" }
\end{array}
$$

The predicate logic of order $\mathrm{N}$ provides rich semantic for representing the procedures. For example the following expression:

ACTION-T(ACTOR-S,ACTION-R(ACTOR-Q,OBJECT -P))

Can be interpreted as "... the ACTOR-S applies the ACTION-T on what is the result of that ACTOR-Q applies the ACTION-R on the OBJECT-P ...".

\section{Proposed Formalism: Sequence Diagram of Group Dynamics}

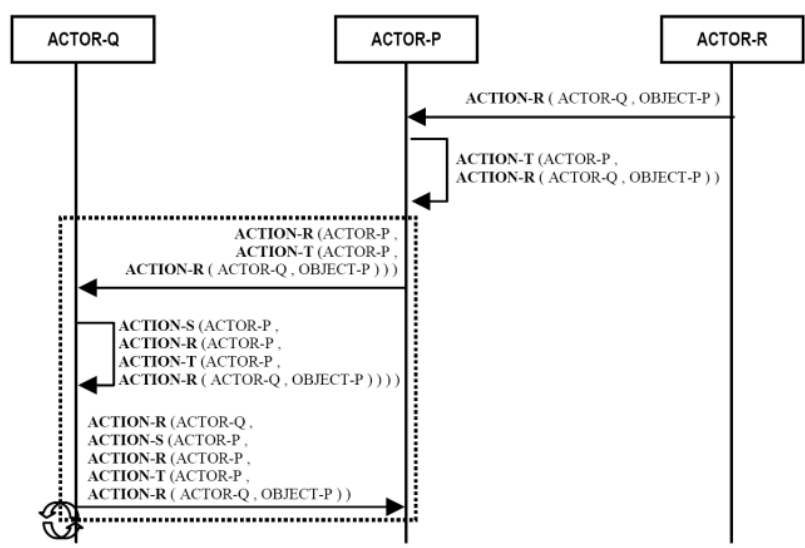

Fig. 3. Sequence diagram of group dynamics corresponding to theoretical example.

To express the group dynamics among the actors in the timeline imposed by the procedures of interaction, the authors have introduced in previous works [16], [21] the Sequence Diagram of Group Dynamics. These diagrams are based on sequence diagrams [17], [18]. An theoretical example of Table CCD is presented in Table III and a 
Sequence Diagram of Group Dynamics is presented in Fig. 3.

TABLE III: TABLE CONCEPT-CATEGORY-DEFINITION CORRESPONDING TO THEORETICAL EXAMPLE

\begin{tabular}{lll}
\hline Concept & Category & Definition \\
\hline ACTOR-Q & Actor & El ACTOR-Q is ... \\
ACTOR-P & Actor & El ACTOR-P is ... \\
ACTOR-R & Actor & El ACTOR-R is ... \\
ACTION-S & Action & El ACTION-S is ... \\
ACTION-T & Action & El ACTION-T is ... \\
ACTION-R & Action & El ACTION-R is ... \\
OBJECT-P & Object & El OBJECT-P is ... \\
\hline
\end{tabular}

\section{E. Proposed Formalism: Diagram of Conceptual Objects Development}

Virtual spaces dedicated to collaborative work are intended to facilitate mediation between teams whose members are not physically contiguous, and have to develop a conceptual object (for example: research, project development, software, thesis plan, technical articles, reports among others). The modelling of interactions in virtual spaces dedicated to collaborative work should help to specify the interactions among group members, and the developing work stages of the conceptual object that the collaborative working team is carrying on. The virtual space for collaborative work must satisfy the requirement of keeping and documenting the different versions of the conceptual object that is being developed by the collaborative working team; leaving a record of the evolution from the agreement between the members of the working group since initial specifications of the conceptual object until its final stage development. For modelling of the transformations of objects is proposed the formalism: Diagram of Conceptual Objects Development. These diagrams are based on Petri Nets [22] and are digraphs with two types of nodes: the "conceptual objects" which will be denoted with circles and the "transformations" that will be denoted by rectangles. The "transformation" represents the action that must to be performed to make evolve the "conceptual object" from a level of development into another. An theoretical example of a Diagram of Conceptual Objects Development is presented in Fig. 4.

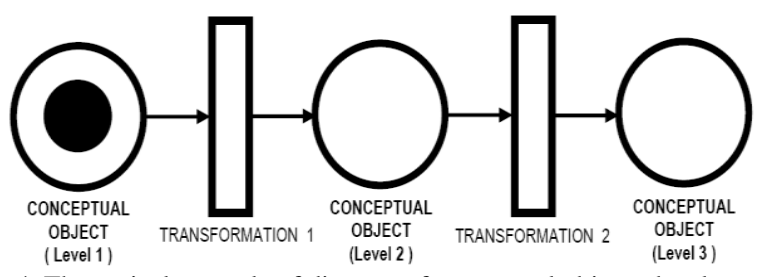

Fig. 4. Theoretical example of diagram of conceptual objects development.

\section{PROOF OF CONCEPT}

To illustrate the proposed formalism is provided a proof of concept based on a case brought in [21]. The situation described in the case is based on developed interactions within a virtual space during the thesis plan review of a master's degree student made by a $\mathrm{PhD}$ degree student (co-director of the master's thesis) under supervision of a senior researcher (director of the master's thesis and doctoral's thesis). The case "Review of Master's Thesis Plan" is described in the following bit of text:

"...Master's degree student sends the PhD degree student, his master's thesis plan developed previously. $\mathrm{PhD}$ degree student reviews the plan and made the corrections and comments that he considers relevant and then send them to master's degree student. He appropriates the corrections and comments to continue working on his master's thesis plan. Once the PhD degree student believes that the version of the master's thesis plan has not problems, forward it to senior researcher asking for his overseeing of the final version of master's thesis plan. Senior researcher oversees the corrections made by the $\mathrm{PhD}$ degree student. As a result of overseeing, he can send comments which may include observations about the correction made and/or to make further corrections to be introduced in master's thesis plan. Upon receiving these comments, the $\mathrm{PhD}$ degree student appropriates these and forwards them to master's degree student for his appropriating also, allowing in this way the generation of new versions of the document ..."

In the case are identified: three actors, one object, eight interactions. These are shown in Table CCD shown in Table IV.

From the actors and interactions identified in Table CCD, interaction cases are presented in Fig. 5. Cases of interaction are integrated in the group interaction diagram that is shown in Fig. 6.

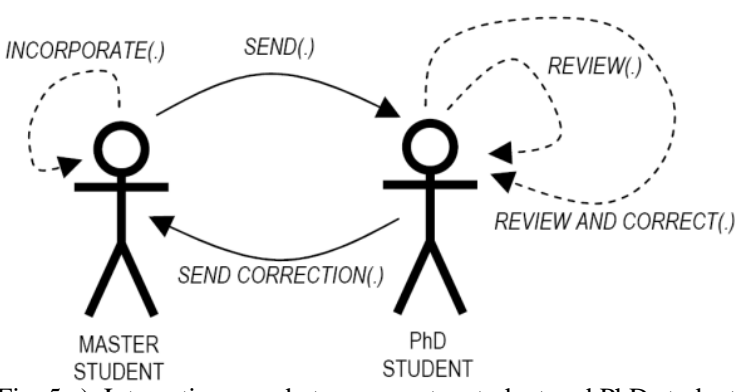

Fig. 5 a). Interaction case between master student and $\mathrm{PhD}$ student.

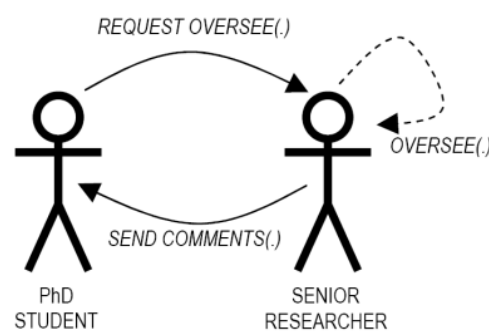

Fig. 5 b). Interaction case between PhD student and senior researcher.

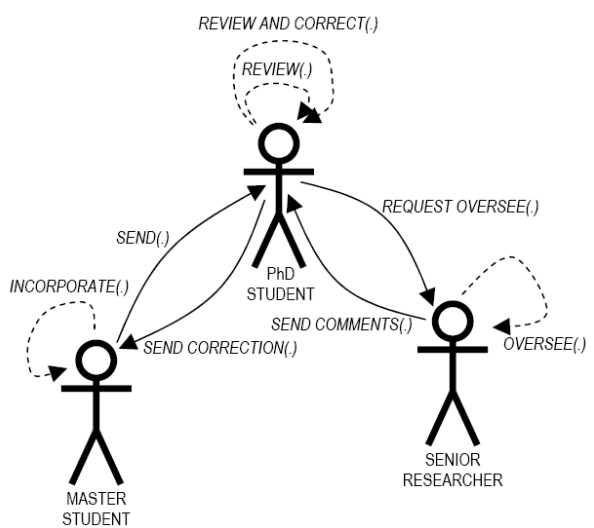

Fig. 6. Group interaction diagram among master student, $\mathrm{PhD}$ student and senior researcher. 
TABLE IV: TABLE CCD OF CASE "REVIEW OF MASTER'S THESIS PLAN"

\begin{tabular}{lllll}
\hline Concept & Category & Definition & \\
\hline INCORPORATE & INTERACTION & Actor "A" incorporates the
\end{tabular}

received information in the document and / or comments in it.

PhD STUDENT ACTOR

SEND

INTERACTION Actor "A" sends to actor "B" a document or information.

SEND

COMMENTS

INTERACTION Actor "A" sends Actor "B" the comments on the results of overseeing carried out, this may include observations about the correction made and/or further corrections to make.

SEND

INTERACTION Actor" A" sends to actor "B" the

CORRECTION

SENIOR

RESEARCHER

ACTOR

MASTER

STUDENT

THESIS PLAN

OBJECT

REVIEW

INTERACTION

result of the review and correction of the document with its observations.

Professional with a $\mathrm{PhD}$ degree or academic equivalent, with scientific production of international importance, with background in project management of $\mathrm{R} \& \mathrm{D}$, with background in human resources training at the doctoral level, master degree, and grade, and acreditation of being investigator category I or II of the Argentine Ministry of Education.

Professional with grade title and who is making a master degree, with national scientific production, with a history of collaboration in the development of human resources at grade level, and acreditation of being investigator category IV or V of the Argentine Ministry of Education.

Document referred to student's research project who is carrying out to earn a $\mathrm{PhD}$, master's, specialty or grade degree.

The actor reviews the document and states his comments (in case needed) but without doing any correction.

REVIEW AND INTERACTION The actor revises and corrects the CORRECT document with indication of his comments and corrections (if it was necessary).

REQUEST

INTERACTION Actor "A" asks oversee of review / corrections on a document generated by a third actor. Overseeing will be made by actor "B".

OVERSEE

INTERACTION

Actor "A" oversees the reviews or corrections made by an actor "B" on a document that has been sent previously to him by a third actor.

The group dynamics that develops among actors within the timeline is expressed through the interaction group diagrams that is shown in Fig. 7. The conceptual object identified is
"Master Thesis Plan" and the Diagram of Conceptual Objects Development is shown in Fig. 8.

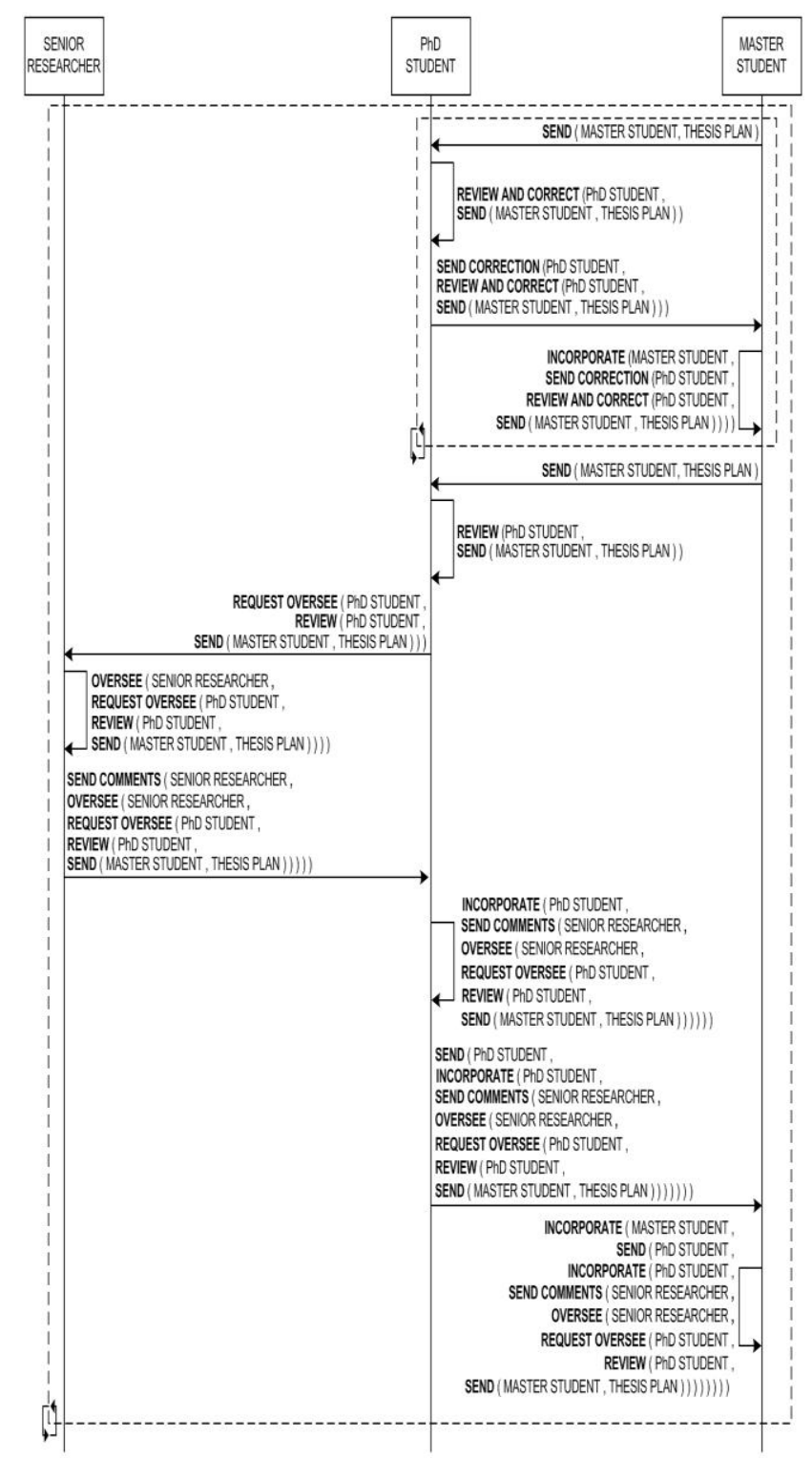

Fig. 7. Interaction group diagram of case "review of master's thesis plan".

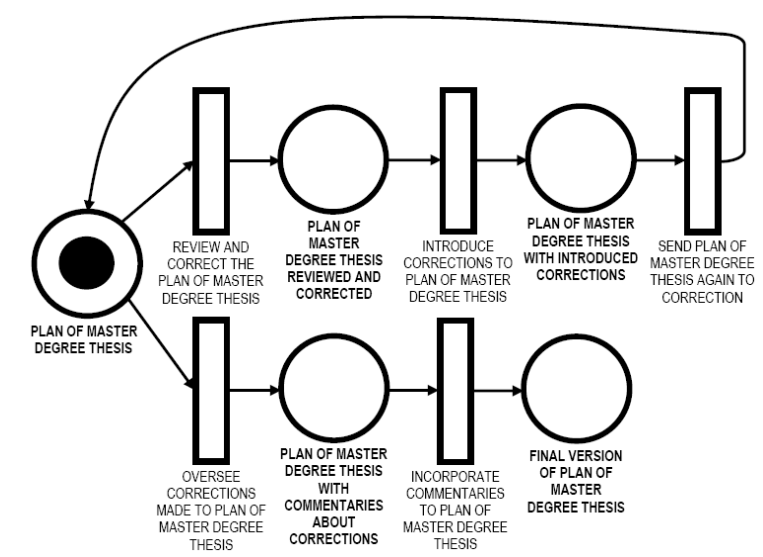

Fig. 8. Diagram of conceptual objects development of case "review of master's thesis plan.

\section{ConCLusions}

Virtual spaces dedicated to collaborative work are emerging as a tool to integrate work teams whose members 
are not physically contiguous. The first experiences in Argentina in the use of such environments have emerged in the University and are linked to the collaboration of researchers from several countries in training human resources in research [21]. The virtual environments used have a low level of integration between its components and do not often have the functionality of asynchronous communication (online) among members of the workgroup. It is perhaps this characteristic that has made evident the need for formalisms for modeling of the interactions between members of the working group and the evolution of conceptual objects they create.

Given this context, this paper has introduced the integrated formalisms: table category-concept-definition, interaction cases and interaction group diagrams, interaction procedures, sequence diagram of group dynamics, and diagram of development of conceptual objects. It has been shown the use of the presented formalisms through a test case taken from recent literature on the subject.

As future line of research work, we are going to validate the generality of the use of the modeling formalisms proposed in two domains: management of software development teams, and management of architectural design teams. Both cases with members no physically contiguous.

\section{REFERENCES}

[1] J. Conde, N. Pereyra, F. Zorzan, A. Ferreira, and J. Guazzone, "Gestión y Seguimiento de Grupos de Trabajo Colaborativos en Entornos Virtuales de Enseñanza y Aprendizaje," Congreso Virtual Iberoamericano de Calidad en Educación a Distancia, 2008.

[2] J. Conde, N. Pereyra, and A. Ferreira, "Diseño de Módulo para trabajo en Grupo," in Proc. IV Congreso de Tecnología en Educación y Educación en Tecnología. Pág, ISBN: 978-950-34-0573-4, 2009, pp. 98-105.

[3] J. Grudin, "Computer-supported cooperative work: history and focus," IEEE Computer, vol. 27, no. 5, pp. 19-26, 1994.

[4] J. Peiro, F. Prieto, and A. Zornoza, "Nuevas Tecnologías Telemáticas y Trabajo Grupal. Una Perspectiva Psicosocial," Psicothema, vol. 5, pp. 287-3005, ISSN: 0214-9915, 1993.

[5] A. Molina, M. Redondo, and M. Ortega, "A review of notations for conceptual modeling of groupware systems," in En New Trends on Human-Computer Interaction, J. Macías, A. Granollers, and P. Latorre Eds., pp. 1-12, ISBN: 978-1-84882-351-8, 2009.

[6] S. Carlsen, "Conceptual modeling and composition of flexible workflow models," $\mathrm{PhD}$ Thesis Department of Computer and Information Science, Faculty of Physics, Informatics and Mathematics, Norwegian University of Science and Technology, 1997.

[7] W. V. der Aalst, P. Barthelmess, C. Ellis, and J. Wainer, "Proclets: a framework for lightweight interacting workflow processes," Journal of Cooperative Information Systems, vol. 10, no. 4, pp. 443-482, 2001.

[8] J. Garrido, "Amenities: una metodología para el desarrollo de sistemas cooperativos basada en modelos de comportamiento y tareas," Tesis Doctoral en Lenguajes y Sistemas Informáticos, Universidad de Granada, 2003.

[9] J. Rubart and P. Dawabi, "Towards uml-g: a uml profile for modeling groupware," Lecture Notes in Computer Science, vol. 2440, pp. 93-113, ISSN: 0302-9743, 2002.
[10] J. Rubart and P. Dawabi, "Shared data modeling with UML-G," International Journal of Computer Applications in Technology, vol. 19, no. 3/4, pp. 231-243, 2004

[11] M. Sosa, R. Zarco, and A. Postiglioni, "Modelando Aspectos de Grupo en Entornos Colaborativos para Proyectos de Investigación," Revista de Informática Educativa y Medios Audiovisuales, vol. 3, pp. 22-31. ISSN: 1667-8338, 2006.

[12] W. Giraldo, A. Molina, C. Collazos, M. Ortega, and M. Redondo, "Taxonomy for Integrating Models in the Development of Interactive Groupware Systems," Journal of Universal Computer Science, vol. 14, no. 19, pp. 3142-3159, 2008.

[13] A. Molina, M. Redondo, M. Ortega, and U. Hoppe, "Ciam: a methodology for the development of groupware user interfaces," Journal of Universal Computer Science, vol. 14, no. 9, pp. 1435-1446, 2008.

[14] A. Gómez, N. Juristo, C. Montes, and J. Pazos, "Ingeniería de conocimiento," Editorial Centro de Estudio Ramón Areces, ISBN: 84-8004-269-9, 1997.

[15] P. Britos et al., Ingeniería de Sistemas Expertos, Ed., Nueva Librería, ISBN: 987-1104-15-4, 2004.

[16] D. Rodríguez, F. Pollo-Cattaneo, R. Bertone, and R. García-Martínez, "Elementos para el análisis y diseño conceptual de espacios virtuales de trabajo colaborativo orientados a la formación de investigadores," in Proc. XVI Congreso Argentino de Ciencias de la Computación, ISBN: 978-950-9474-49-9, pp. 364-373, 2010.

[17] G. Booch, J. Rumbaugh, and I. Jacobson, The Unified Modelling Language Users Guide, Adison Wesley Publishing Co. ISBN: 0-201-57168-4, 1998.

[18] K. Kendall and J. Kendall, Análisis y diseño de sistemas, PearsonPrentice Hall, ISBN: 970-26-0577-6, 2005.

[19] J. Cuena, Lógica informática. alianza editorial, ISBN: 84-2068601-8, 1985.

[20] F. Naishtat, "Lógica para computación,” Eudeba, ISBN 950-23-0282-6, 1986.

[21] D. Rodríguez, "Espacios virtuales para la formación de investigadores, elementos de análisis y diseño," Tesis de Maestría en Tecnología Informática Aplicada a la Educación, Universidad Nacional de La Plata, 2012.

[22] C. Petri, "Kommunikation mit automaten," $\mathrm{PhD}$ Thesis, Institute für Instrumentelle Mathematik, Bonn, Germany, 1962.

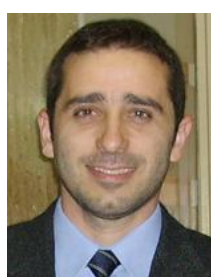

Dario Rodriguez received the B.A. in multimedia design from Da Vinci College in 2005 (Buenos Aires, Argentina), the Diploma degree in audiovisual communication from Argentine Social Museum University (UMSA) in 2007 (Buenos Aires, Argentina), and the M.S. on Information Technology Applied to Education from National University of La Plata in 2012 (La Plata, Argentina). He is director of the Research and Development Laboratory in Work Virtual Spaces of National University of Lanus (Argentina) since 2009.

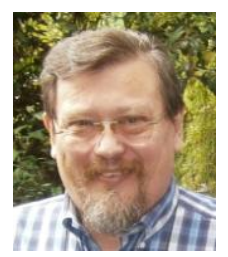

Ramón García-Martínez received the B.S. in computer science from National University of La Plata in 1988 and M.S. and Ph.D. degrees in computer science from Polytechnic University of Madrid in 1992 and 1997, respectively. He is Founder Director of the Information Systems Research Group of National University of Lanus (Argentina) since 2008. He was Founder Director of the Intelligent Systems Laboratory of the School of Engineering of the University of Buenos Aires (Argentina) during 1994-2008 and Director of the Software and Knowledge Engineering Center of the Graduate School of the Buenos Aires Institute of Technology (Argentina) during 2000-2008. 